\title{
VAŽNOST PRIMJENE FINANSIJSKOG IZVJEŠTVANJA ZA RAZVOJ KORPORATIVNOG UPRAVLJANJA
}

\author{
Snježana Stanišić \\ Fakultet za poslovnu ekonomiju, Univerzitet Sinergija, Bijeljina, Republika Srpska
}

\section{Apstrakt:}

Upravljanje bilo kojom organizacijom uključuje donošenje odluka i rješavanje problema pa je za tu svrhu neophodno posjedovati određene informacije i određena znanja. U informacioni sistem preduzeća slivaju se podaci i informacije iz osnovnih funkcijskih procesa preduzeća, te informacije mogu dolaziti iz spoljnog svijeta i iz same organizacije. Značaj informacija koje se javljaju kao produkt računovodstva ogleda se, $\mathrm{s}$ jedne strane, $\mathrm{u}$ tome što se one koriste prilikom polaganja računa o poslovanju preduzeća pred investitorima, kreditorima, poslovnim partnerima, državi i ostalim korisnicima. Dok s druge strane, imamo njihovu nezamjenjliivu ulogu kada je u pitanju pružanje potrebnih podataka prilikom realizacije upravljačkih aktivnosti preduzeća, koje se sastoje u polaganju računa o stanju i uspjehu preduzeća, donošenja pojedinačnih poslovno - finansijskih procesa u preduzeću. Menadžment preduzeća realizuje svoje aktivnosti na osnovu instrumenata finansijskog izvještavanja.
\end{abstract}

\section{UVOD}

Savremeno finansijsko upravljanje zasniva se na informacijama i rezultatima sistemskog praćenja, prikupljanja, obrade i obračuna složenih pokazatelja finansijskog poslovanja. Navedeni postupci predstavljaju osnovu za finansijsku analizu poslovanja preduzeća. Finansijska analiza obuhvata analizu prinosnog, imovinskog i finansijskog položaja preduzeća, u cilju dobijanja informacija koje predstavljaju polaznu osnovu za preduzimanje mjera i akcija usmjerenih na popravljanje trendova u poslovanju i razvoju preduzeća. Bitan segment finansijske funkcije preduzeća je precizna analiza finansijskog položaja preduzeća ispitivanjem finansijskih izvještaja preduzeća. Finansijski položaj preduzeća pokazuje usklađenost sredstava, zaduženost, solventnost, mogućnost održavanja realne vrijednosti kapitala i reprodukcionu sposobnost preduzeća. Analizom finansijskog položaja procjenjuje se mogućnost izmirenja obaveza, uvećanja sopstvenog kapitala i mogućnost finansiranja reprodukcije. Menadžment preduzeća ima obavezu da održava dobar finansijski položaj. Ako su indikatori finansijskog položaja nepovoljni, menadžment preduzeća mora da reaguje kako se opstanak i razvoj preduzeća ne bi ugrozio. Dobar finansijski položaj je važan pokazatelj i bankama prilikom donošenja odluka o odobravanju kredita, dobavljačima prilikom davanja robe na odloženo plaćanje kao i prema drugim poslovnim partnerima. Računovodstveni izvještaji, sa odgovarajućim informacionim sadržajem predstavljaju jedan od najbitnijih i najpouzdanijih instrumenata menadžmenta. Osnovni računovodstveni izvještaji iz finansijskog i upravljačkog računovodstva, predstavljaju nezamjenjljiv informacioni izvor za analizu i ocjenu finansijskog, kako kratkoročnog, tako i dugoročnog, položaja preduzeća. Osnovna pretpostavka korišćenja računovodstvenih izvještaja za potrebe menadžmenta, jeste njihov kvalitet određen pouzdanošću, razumljivošću i blagovremenošću, a što je uslovljeno odgovarajućom organizacijom i upravljanjem računovodstvenih informacionih sistema.

\section{UPRAVLJANJE PREDUZEĆEM I STRATEGIJSKO ODLUČIVANJE}

Upravljanje preduzećem predstavlja donošenje i sprovođenje strategijskih odluka od strane organa upravljanja. Strategijsko odlučivanje odnosi se na teorijsku, praktičnu pripremu i upotrebu cjelokupnog potencijala preduzeća i njegovih dijelova, radi povećanja profita i kapitala. U slučaju stečaja ili prestanka rada preduzeća, određene aktivnosti u funkciji upravljanja i nadzora, mogu preuzeti povjerioci sa većinskim potraživanjima. Ovo pravo značajnih povjerilaca treba da bude predviđeno $\mathrm{u}$ ugovorima o kreditu ili zajedničkom poslu, odnosno investicijama [3]. Rad organa koji upravljaju preduzećem je javan. Organi upravljanja preduzećem su: skupština, upravni odbor, nadzorni odbor. Skupština i upravni odbor upravljaju poslovanjem i investicijama preduzeća. Nadzorni odbor vrši nadzor nad poslovanjem i upravljanjem preduzeća, dok Upravni odbor i direktor čine upravu preduzeća. Odvajanje vlasništva od upravljanja bitna je karakteristika preduzeća. Za razliku od preduzeća u vlasništvu pojedinca gdje je vlasnik istovremeno i menadžer, odvajanje vlasništva i upravljanja osigurava preduzećima postojanost [5].

Vlasnici kapitala neprekidno su obavješteni o poslovanju i interesima preduzeća putem planova poslovanja i investicija, računovodstvenih i statističkih bilansa i na osnovu izvještaja skupštine, upravnog i nadzornog odbora. Oni imaju pravo uvida u poslovne knjige i dokumenta preduzeća i uvida u organizacione, upravljačke promjene u preduzeću. Kada utvrdi nastajanje znatnog gubitka i bitno smanjenje ukupnog kapitala preduzeća, upravni ili nadzorni odbor preduzeća saziva vanrednu skupštinu preduzeća. Nadzorni odbor ima pravo uvida u poslovne knjige i sva dokumenta preduzeća. Direktor i upravni odbor su dužni da nadzornom odboru daju sva obavještenja o poslovanju i investicijama preduzeća i omoguće njegov nesmetan rad. Nadzorni odbor je dužan da zahtjeva vanredni sasta- 
nak skupštine preduzeća kada utvrdi teže nepravilnosti u radu preduzeća i veće povrede njihovih interesa i interesa vlasnika kapitala i vlasnika rada.

\subsection{Kvalitativni oblik finansijskog izvještavanja}

Karakter kvalitetnih finansijskih izvještaja, poprimaju finansijski izvještaji rađeni prema međunarodnoj profesionalnoj regulativi koji se odlikuju relevantnim i vjerodostojnim informacijama. Kvalitetno finansijsko izvještavanje doprinosi ranom prepoznavanju i razumjevanju signala i uzroka ulaska u ekonomsku i finansijsku krizu i ima pozitivan uticaj na ukupna ekonomska kretanja. Neophodnost kvalitetnog finansijskog izvještavanja sve više dobija na značaju. Povećava se broj korisnika informacija iz finansijskih izvještaja, što, pored ostalog, jača i potrebu za uspostavljanjem Sistema javnog nadzora i kontrole kvaliteta. Savremeni koncept kontrole kvaliteta podrazumjeva uvođenje standarda kvaliteta finansijskog izvještavanja [6]. Kvalitetan sistem finansijskog izvještavanja je veoma važan jer obezbjeđuje odgovarajuće informacije na osnovu kojih će investitori donijeti najbolje odluke o ulaganju kapitala. Kvalitetno finansijsko izvještavanje smanjuje informacione rizike što je od velikog značaja za sigurnost učesnika na tržištu kapitala, stabilnost finansijskog Sistema i smanjenje rizika od finansijskih kriza. U pokušaju suštinskog određenja koncepta kvaliteta finansijskih izvještaja mora se poći od sintetizovanih kvalitativnih karakteristika finansijskih izvještaja datih u Konceptualnom okviru finansijskog izvještavanja (Conceptual Framework for Financial Reporting). Konceptualni okvir finansijskog izvještavanja ne predstavlja standard koji se mora poštovati, već on pomaže pri formulisanju Međunarodnih računovodstvenih standarda i tumačenju informacija sadržanih u finansijskim izvještajima [7]. Svoj potpun značaj u uslovima globalizacije tržišta, imaju finansijski izvještaji sastavljeni prema Međunarodnim računovodstvenim standardima, i na taj način vrši se otvaranje nacionalnih privreda prema svijetu, sa sve bržim razvojem informacioni i komunikacionih tehnologija.

\subsection{Značaj informacija za proces upravljanja preduzeća}

Problematika procesa upravljanja u preduzeću vezana je za pravovremene i prikladne informacije i njihovu pravilnu primjenu. Ispravnost donesenih poslovnih odluka zasniva se i u mnogo čemu zavisi od, na odgovarajući način, organizovanog informacionog sistema preduzeća, pod kojim se ne podrazumjeva samo sistem dobijanja i obrade podataka, već i sistem formiranja ocjena o poslovnim pojavama. Menadžment preduzeća u procesu donošenja poslovnih odluka vrši odabir jedne od dvije ili više mogućih akcija u nekoj situaciji, koje će biti preduzete da bi se postigao neki cilj u bližoj ili daljoj budućnosti.

Informacije treba shvatiti kao jedan od resursa koji menadžmentu stoje na raspolaganju, kao što su važni, na primjer, resursi materijala, energetski resursi, ljudski resursi, finansijski resursi i slično, tako su važni i informacijoni resursi. Ukoliko informacije shvatamo kao resurs onda je moguće upravljati njima, kao što je moguće i sa drugim resursima, pri tom je veoma bitno da osoblje koje je zaduženo za upravljanje informacijama ima ne samo reaktivnu, već i proaktivnu ulogu u upravljanju informacionim sistemom, jer se na samo takav način mogu dobiti relevantne informacije za donošenje poslovnih odluka u preduzeću [2].

Upravljanje bilo kojom organizacijom uključuje donošenje odluka i rješavanje problema pa je za tu svrhu neophodno posjedovati određene informacije i određena znanja. U informacioni sistem preduzeća slivaju se podaci i informacije iz svih osnovnih funkcijskih procesa preduzeća, te informacije mogu dolaziti iz spoljnjeg svijeta i iz same organizacije. Tako da se može reći da se odlučivanje o smjernicama poslovanja preduzeća zasniva na rezultatima stručne analize podataka i informacija.

Razvoj jednog informacionog sistema je dinamičan proces koji zavisi od mnogo faktora poput veličine preduzeća, razvoja organizacije i nivoa razvijenosti tehnologije. Značaj informacija koje se javljaju kao produkt računovodstva ogleda se, s jedne strane, u tome što se one koriste prilikom polaganja računa o poslovanju preduzeća pred investitorima, kreditorima, sindikatom i ostalim korisnicima od strane menadžmenta. Dok s druge strane, imamo njihovu nezamjenjljivu ulogu kada je u pitanju pružanje potrebnih podataka prilikom realizacije upravljačkih aktivnosti preduzeća, koje se sastoje u polaganju računa o stanju i uspjehu preduzeća, donošenja pojedinačnih poslovno- finansijskih procesa u preduzeću. Za upravljačke svrhe potrebno je da računovodstvene informacije posjeduju, prije svega, relevantnost i pouzdanost jer mogu biti predmet pažnje velikog broja zainteresovanih strana. Menadžment preduzeća realizuje svoje aktivnosti u zavisnosti od ovlašćenja i odgovornosti, na različitim nivoima odlučivanja - strateškom, taktičkom i operativnom - prvenstveno uz pomoć informacione podrške upravljačkog računovodstva, ali i na osnovu instrumenata finansijskog izvještavanja, koji su prije svega relevantni za najviše upravljačke nivoe. Računovodstveno informacioni sistem ima ulogu informacione baze funkcije upravljanja, koji ima najneposredniji uticaj na opšti kvalitet, a prije svega na pouzdanost računovodstvenih podataka, pokazatelja i informacija na kojima se temelje poslovne odluke. Uspješno upravljanje preduzećem u nadležnosti je menadžmenta i podrazumjeva efektivnu i efikasnu realizaciju ciljeva preduzeća.

\subsection{Finansijsko izvještavanje u konceptu korporativnog upravljanja}

Uspjeh menadžmenta u odlučivanju i kontroli poslovno finansijskih procesa preduzeća zavisi od količine i kvaliteta raspoloživih informacija. Sam proces upravljanja preduzećem predstavlja rad sa informacijama, samim tim uspješno upravljanje poslovnim sistemima teško se može i zamisliti bez raspolaganja velikim brojem relevantnih i pouzdanih informacija. Menadžment vodi i usmjerava poslovni sistem tako što neprekidno predviđa njegovu rentabilnost i rentabilnost njegovih objekata i segmenata aktivnosti i prati njihova ostvarenja. Mjerenje rentabilnosti je problem računovodstvenog informacionog sistema, koga kontrolišu finansijsko i upravljačko računovodstvo. Ovakva podjela računovodstvenog informacionog sistema bazirana je na potrebi za stvaranjem informacione osnove za obavljanje aktivnosti različitih interesnih grupa izvan eksternih i internih korisnika. Eksterni korisnici se interesuju za poslovno - finansijski život preduzeća, a interni korisnici, prvenstveno menadžeri, imaju obavezu i interes da vode preduzeće ka željenom cilju. Informacije dobijene preko finansijskih izvještaja - bilans stanja, bilans uspjeha, izvještaja o novčanim tokovima, izvještaj o promjenama na kapitalu, koji su obavezno praćeni napomenama - koji su produkt računovodstvenog informacionog sistema, odnosno, finansijskog računovodstva prezentuju se eksternim korisnicima. Ovi korisnici su: sadašnji i potencijalni akcionari, investitori, kreditori, poslovni partneri, država, zaposleni i ostala društvena javnost. Informacije iz finansijskih izvještaja zadovoljavaju potrebe ovih korisnika koji na osnovu njih donose poslovne odluke u usmjeravanju ponašanja preduzeća $u$ budućnosti. Finansijski izvještaji su osnov za donošenje odluka o investiranju, odobravanje kreditnih aranžmana po iznosu i vremenu vraćanja, isporuci proizvoda i slično.

Analiza uspješnosti - rentabilnosti takvog upravljanja, finansijskog položaja i potencijala preduzeća i promjena finansijskog položaja baziraju se na finansijskim izvještajima koji zajedno sa analizom predstavljaju dvije strane jedne medalje. Bez analize nema valjanih poslovnih i finansijskih izvještaja a 
bez poslovnih i finansijskih izvještaja nema potrebe za analizom [1]. Menadžment poslovnog sistema, kao što je poznato, čine menadžeri na vrhovnom, srednjem i operativnom nivou njegove organizacione i upravljačke strukture. Na svim ovim nivoima postoji potreba za razdvanjem nadležnosti i odgovornosti za donošenje relevantnih odluka, koja ne utiču samo na određeni nivo već utiču na sve nivoe menadžmenta.

Uspješan finansijski menadžer vodi svoje preduzeće prema ulaganjima u projekte koji povećavaju vrijednost više nego što to ulaganje zahtjeva. Pored odlučivanja, svi nivoi menadžmenta u poslovnom sistemu obavljaju i druge upravljačke aktivnosti, kao što su: planiranje, kontrola, organizovanje, komuniciranje i motivisanje. Informacionu osnovu za obavljanje ukupnih upravljačkih aktivnosti čini upravljačko računovodstvo, kao interno orijentisani dio računovodstvenog informacionog sistema [5].

Donošenje niza strateških i operativnih odluka od strane menadžera na svim nivoima upravljanja vezane su, prije svega za, proizvod, cijene i asortiman, poslovni i vremenski raspored proizvodnje, zalihe, kreditiranje kupaca, kapitalna ulaganja, rekonstrukciju postojećih i izgradnji novih koncepata, spajanje ili pripajanje preduzeća ili dijelova, stimulisanje menadžera i slično. Menadžeri su prinuđeni da u procesu donošenja odluka planiraju svoje aktivnosti u skladu sa obimom preuzetih nadležnosti i odgovornosti, radi predviđanja nastanka mogućih problema, kao i blagovremene pripreme za njihovo rješavanje, ali i da prate ostvarenja kako bi imali uvida u to da li se ostvarenja odvijaju na nivou planiranih vrijednosti.

Finansije pomažu menadžerima da procjenjuju poslovne mogućnosti, alternative koje su im na raspolaganju i pomaže im da prate odluke koje se već primjenjuju. Takvo praćenje je važno za razvoj korporativne strategije koje pomaže menadžerima da promjene ili usklade svoju strategiju temeljem rezultata prethodnih strateških odluka [4]. Rezultat dobro promišljenih i pažljivo praćenih poslovnih odluka je veći očekivani novčani tok preduzeća u budućnosti. Osim uticaja na buduće novčane tokove, poslovne odluke često mogu uticati i na trenutne finansijske odluke. Finansijske i investicione odluke su međusobno povezane i mogu biti dugoročne i kratkoročne. U slučaju da preduzeće prodaje proizvode i usluge na kredit, mora biti sigurna da će kupci na vrijeme platiti svoje račune. Preduzeće koje posluje na međunarodnom tržištu mora stalno konvertovati različite valute. Proizvodna preduzeća moraju odlučiti koliko će ulagati u zalihe sirovina i gotovih proizvoda [5]. Najveći rizik snose ona preduzeća koja ne prate pažljivo svoje kupce. Odgovornost finansijskog menadžera je prikupljanje novčanih sredstava koja su preduzeću potrebna za investiranje i redovno poslovanje. Finansijski menadžer mora identifikovati rizike i pobrinuti se da upravlja pravilno jer poslovanje samo po sebi rizično.

\section{ZAKLJUČAK}

Analiza finansijskog položaja preduzeća treba da odredi trenutni položaj preduzeća, kako bi se na osnovu rezultata analize definisale mjere za eventualno poboljšanje finansijskog položaja preduzeća. Strategijsko odlučivanje odnosi se na teorijsku i praktičnu pripremu i upotrebu cjelokupnog potencijala preduzeća i njegovih dijelova, radi povetanja profita i kapitala. U informacioni sistem preduzeća slivaju se podaci i informacije iz svih osnovnih funkcijskih procesa preduzeća, te informacije mogu dolaziti iz spoljnjeg svijeta i iz same organizacije, tako da se može reći da se odlučivanje o smjernicama poslovanja preduzeća zasniva na rezultatima stručne analize podataka i informacija. Informacije iz finansijskih izvještaja zadovoljavaju potrebe ovih korisnika koji na osnovu njih donose poslovne odluke u usmjeravanju ponašanja preduzeća u budućnosti. Finansijski izvještaji su osnov za donošenje odluka o investiranju, odobravanje kreditnih aranžmana po iznosu i vremenu vraćanja, isporuci proizvoda i slično.

\section{LITERATURA}

[1] Malešević, Đ.,Vranković, M., Poslovna analiza, Ekonomski fakultet, Subotica, 2007.str. 258

[2] Mihailović, I.,Računovodstvene informacije kao podloga menadžmentu za donošenje poslovnih odluka, Ekonomika, Niš, 1999. str. 35.

[3] Mileusnić, N., Menadžment preduzeća, Savez računovođa i revizora Srbije, Beograd, 1998.str. 39.

[4] M.P.Narayanan, Finansije za strateško odlučivanje, Mate, Zagreb, 2007.str. 72 .

[5] R. Barley, S. Mayers, A. Marcus, Osnovi korporativnih finansija, Mate, Zagreb, 2007.str.156 ( prevod sa engleskog jezika )

[6] Program i akcioni plan unapređivanja i razvoja računovodstvene i revizorske profesije u Republici Srpskoj od 2012. do 2014. godine, (pristup 01.11.2014.) [dostupno na http// www.vladars.net ]

[7] Uloga i značaj kvalitetnog finansijskog izvještavanja, (pristup 31.10.2014.), [dostupno na http// www.ubs-asb.com]

\section{IMPORTANCE OF THE FINANCIAL REPORTING IMPLEMENTATION FOR THE CORPORATE GOVERNANCE DEVELOPMENT}

\section{Snježana Stanišić}

Faculty for business economy, University Sinergija, Raje Baničića bb, Bijeljina, Republic of Srpska, sstanisic@sinergija.edu.ba

\footnotetext{
Abstract:

Managment of any entity includes decision making and problem solving; therefore in order to complete those activities it is necessary to obtain specific information and certain knowlage. The entity's information system is contained out of the data and information gatherd from the basic business functions and they could be produced within or outside of the entity. The inportance of the accouting information is reflected, on the one hand, in the fact that they are used to report the financial condition and profitability to investors, creditors, business partners, goverment and others stakeholders. While on the ther hand, there is their irreplacesble role when it comes to providing the necessary data during the realization of basic business activities of the entyty. The aforementioned data consists of information regarding the financial condition and profitability and decision making process of certain entity. The managment completes those activites by using the financial reporting instruents.
}

\section{Key words:}

accounting data, managment, financial process, company managment. 